\title{
Morphological and Bitterness Level Characterization of Phyllanthus emblica Drupes Reveals Higher Diversity
}

\author{
Mawalagedera S.M.U.P. ${ }^{1}$, Perera G.A.D. ${ }^{2}$, Premalal G.G.C. ${ }^{3}$ and \\ Sooriyapathirana S.D.S.S. ${ }^{*}$ \\ ${ }^{1}$ Department of Molecular Biology and Biotechnology, University of Peradeniya, \\ Peradeniya, Sri Lanka \\ ${ }^{2}$ Department of Botany, University of Peradeniya, Peradeniya, Sri Lanka \\ ${ }^{3}$ Veterinary Research Institute, Gannoruwa, Peradeniya, Sri Lanka \\ *sunethss09@gmail.com
}

\begin{abstract}
Phyllanthus emblica L. (V. Nelli) is an important constituent of indigenous medicine and a commercially important fresh fruit species. The diversity of the P. emblica germplasm in Sri Lanka has not been studied in detail according to our knowledge. Therefore, the present study was conducted to characterize the drupes of $P$. emblica gremplasm in Sri Lanka.

A total of 475 P. emblica drupes harvested from 66 trees in selected areas of Anuradhapura, Kandy and Kurunegala districts of Sri Lanka. For each drupe, seven morphometric data; drupe height, width, weigh, mesocarp thickness, stone width, height and weight were measured. Also 61 drupes were used for the quantitative analysis of the epicarp colour of drupes using a colourimeter. An organoleptic property; bitterness was analysed in relation to drupe size by having a taste panel of independent human subjects. The data were analysed using parametric and non parametric statistical methods.
\end{abstract}

The cluster analysis based on drupe size traits clearly characterized the $P$. emblica germplasm in to four clusters. The means of drupe weight (Cluster 1; $5.98 \mathrm{~g}$, Cluster 2; $3.59 \mathrm{~g}$, Cluster 3; $2.13 \mathrm{~g}$, Cluster $4 ; 14.21 \mathrm{~g})$ were significantly different $(P<0.05)$ among the four clusters. There were significant differences in colour metrics between small and large drupe groups. The results indicated that the smaller drupes (chroma; 21.64, hue angle; -10.86) are lighter, yellowish, sharper and less colourful (i.e. dull) than that of the larger drupes (chroma; 12.66, hue angle; -21.11). The sensory data analysis revealed that generally smaller drupes are bitterer (57\% of drupes awfully bitter) in contrast to larger drupes (47\% of the drupes mildly bitter) but there is no guarantee that small drupes are always bitter. The Crarmer's V coefficient (0.47) indicated that the association between drupe size and the bitterness has no perfect linear relationship (Crarmer's V coefficient is 1.00 for such a linear perfect relationship). The drupe traits were not different with respect to their tree locations or the climate and the environmental factors contributed less than other factors such as genetics. The P. emblica germplasm has a higher diversity in Sri Lanka and should be conserved in order to maintain the genetic stochasticity. It sets the foundation to implement conservation measures and this diversity structure can be further verified by molecular portrayal which is currently undertaken by our research group. The proposed characterization can be used as a guideline to define a working level core-collection that will be useful in taking decisions for germplasm conservation and in planning crop improvement programs of $P$. emblica.

Keywords: Phyllanthus emblica, Morphological characterization, Germplasm conservation 